\title{
The influence of collaborative learning games within different devices on student's learning performance and behaviours
}

\author{
Hsien-Sheng Hsiao, Cheng-Sian Chang, Chien-Yu Lin, Chih-Chun Chang, Jyun-Chen Chen \\ Department of Technology Application and Human Resource Development, \\ National Taiwan Normal University, Taiwan
}

\begin{abstract}
This study demonstrates the effectiveness of using multi-touch tabletop collaborative game (MTCG) as a collaborative learning platform, in which multiple students can play games using a digital surface. The learning performance of participants is also explored, along with their related behaviours and their experiences. Consisting of 49 Taipei elementary school fifth graders ranging from 11 to 12 years old, the study participants came from two classes taught by the same teacher. The class assigned as the experimental group used large multi-touch tabletops, while the other class assigned as the control group used personal computers. Analysis results indicated that the experimental group more significantly improved in learning performance and retention than the control group did. Moreover, learning behaviour results of the participants further indicated that the experimental group achieved a better behaviour transfer and more meaningful cyclical learning patterns than the control group did. Importantly, by bridging the gap between digital game-based learning and collaborative learning, this study provides evidence of novel and engaging experiences when using a multi-player, multi-modal tabletop display.
\end{abstract}

\section{Introduction}

Learning as a social interaction can be viewed as collaborative learning (Chen, Chang, Lin, \& Yu, 2009). Collaborative learning is characterised by the interaction between individuals engaged in collaborative learning activities - from divergent perspectives to shared knowledge building (Puntambekar, 2006). Johnson and Johnson (1991) asserted that successful collaborative learning consists of five main elements; positive interdependences, face-to-face promotion of interactions, individual accountabilities/personal responsibilities, interpersonal/small-group skills, and group processing.

Mobile computing advances have ushered in opportunities for students to use handheld devices in order to communicate more freely and complete learning tasks, subsequently enhancing face-to-face collaboration (Cortez, Nussbaum, Woywood, \& Aravena, 2009; Liu \& Kao, 2007). However, face-to-face collaborative activities must consider both task completion and social interaction in teamwork (Pinelle, Gutwin, \& Greenberg, 2003). Collaborative learning on tasks through face-to-face teamwork facilitates the knowledge of students cooperating with each other more meaningfully and extensively than by individual effort (Scardamalia, 2002). Moreover, students engaged in face-to-face learning activities experience improved social interaction with other students (e.g., observing the facial expressions and gestures of other students and identifying problematic areas, immediately improving communication and creating expression approaches absent in remote collaboration).

Large multi-touch tabletops (LMTs) allow users to interact with each other easily on the same screen (Piper, O'Brien, Morris, \& Winograd, 2006; Rick, Rogers, Haig, \& Yuill, 2009). For instance, a 30-inch multi-touch screen that simultaneously allows learners to operate digital multimedia as a collaborative learning platform is commercially available. In contrast to traditional equipment, which limits its use to one operator, the multi-touch screen facilitates group work in a collaborative learning environment (Piper et al., 2006; Rick, Rogers et al., 2009). Stanton and Neale (2003) found that pairs of children using two mice divided their task and worked in parallel, whereas children sharing one mouse demonstrated various behaviours, ranging from highly collaborative work to extreme domination by one partner. Scott, Mandryk, and Inkpen (2003) indicated that when using a shared display for multi-user interaction, students exhibited collaborative behaviours closely resembling their interactions during face-to-face learning activities.

Highly promising for co-located face-to-face work and social interaction, LMTs provide a highly effective means of manipulating virtual objects directly (Quigley, Subramanian, \& Izadi, 2009; Schubert, George, \& Serna, 2012). LMTs have received considerable attention in student participation in 
collaborative learning involving language learning (Morris et al., 2010), problem-solving skills (Hung, Chang, Yu, \& Cheng, 2012), and social skills development (Higgins, Mercier, Burd, \& Hatch, 2011; Piper et al., 2006). These devices allow users to operate directly and collectively on the same screen, subsequently improving interaction effects and simplifying face-to-face interaction in teaching and learning (Rick, Harris et al., 2009). Rick, Rogers et al., (2009) indicated that LMTs have increasingly provided shareable interfaces in which multiple users can interact simultaneously, enabling co-located groups to collaborate more flexibly than when using personal computers.

Many LMTs are commercially available. For example Nlighten Inc manufactures a 60-inch multi-touch screen device. Capable of supporting 32 simultaneous inputs, this device provides face-to-face discussion capabilities to its users, as shown in Figure 1(a). Equipped with a Windows 7 operating system, the device provides an open-ended programming environment and a sufficiently large screen size, explaining the reason we chose this device as the experiment tool in this study. Another example, Smart Skin, manufactured by Computer Science Laboratories Inc. in Japan, recognizes the shape of user hands to calculate the coordinates of the touch points, as shown in Figure 1(b). With 30-inch screens and integrated hardware and software technologies, Microsoft Surface and Smart Table provide a novel computer hardware interface in which users can use fingers and voice to control the devices, as shown in Figures 1(c) and 1(d).

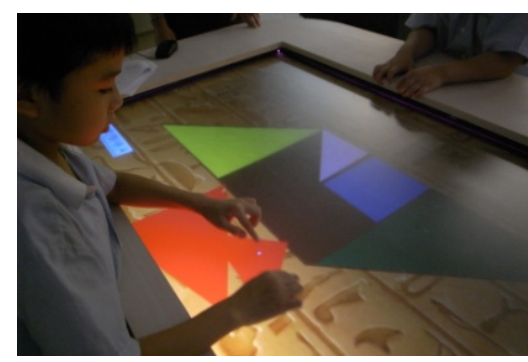

(a). Nlighten

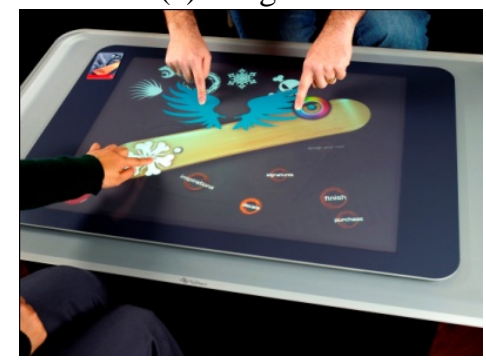

(c). Microsoft surface

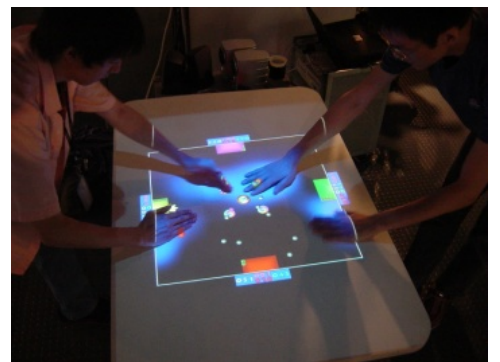

(b). SmartSkin

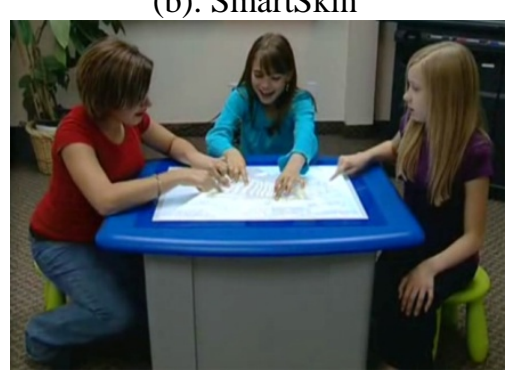

(d). Smart table

Figure 1. The educational applications of large multi-touch tabletops

Digital game-based learning, a newly emerging and highly exciting medium, actively engages students in learning via interactive entertainment (Prensky, 2007). Games, especially for children, play an important role in cognitive development, providing virtual experiences that hold their interest (Mitchell \& Savill-Smith, 2004) because they contain elements of fantasy, curiosity, and challenge (Baltra, 1990; Malone, 1981). Kiili (2005) indicated that games are a useful means of satisfying the basic requirements of an attractive learning environment and providing students with better learning experiences. Also, the flow state, pioneered by Csikszentmihalyi (1975) in a study of individuals involved in activities such as rock climbing, chess, and dancing, has also improved student learning. Characterised by the complete absorption or engagement in an activity, flow refers to an optimal experience (Csikszentmihalyi, 1991). Therefore, as is widely recognized, digital game-based learning is a highly effective means of improving student learning - enhancing their academic achievements, attracting their interest, increasing their learning motivation, and elevating their higher order thinking skills (Eow, Ali, Mahmud, \& Baki, 2010; Huizenga, Admiraal, Akkerman, \& Dam 2009; Kiili, 2005; Papastergiou, 2009 Prensky, 2007; Shin, Sutherland, Norris, \& Soloway, 2012).

Moreover, collaborative or online games provide social interaction that generates valuable ideas and discussion (Chiang, Shih, Liu, \& Lee, 2011; Eow et al., 2010) as well as improves learning attitudes 
(Chang, Peng, \& Chao, 2009; Liu \& Chu, 2010). Sung and Hwang (2013) indicated that collaborative educational games not only allow students to promote their learning attitudes as well as learning motivation, but also increases their academic achievements and self-efficacy owing to the ability to organize knowledge and share facilities embedded in the collaborative gaming environment. Many interactive games, multi-touch tabletop collaborative games (MTCGs) have been developed to support collaborative learning (Antle, Bevans, Tanenbaum, Seaborn, \& Wang, 2011; Goh, Shou, Tan, \& Lum, 2012; Hung et al., 2012; Rick, Harris et al., 2009). These games allow students to learn by collaborating and interacting with peers. Owing to their alluring characteristics (e.g., entertainment, outcome, and feedback (Hung et al., 2012; Roblyer, 2003), these games are a highly effective means of enhancing learning motivation and performance of students (Papastergiou, 2009; Tüzün, Yılmaz-Soylu, Karakuş, İnal, \& Kizılkaya, 2009; Wang \& Chen, 2010).

In light of the above developments, this study evaluates the effectiveness of a novel MTCG based on digital game-based and collaborative learning theories by incorporating the use of 60-inch LMTs. The learning performance, behaviours and experiences of the study participants are also evaluated using LMTs and personal computers. Two research questions raised from previous studies are as follows:

1. Do different learning instruments (i.e., LMTs vs. personal computers) impact the learning performance and memory retention of students, along with their interactive patterns of collaboration?

2. Do different learning tools (i.e., LMTs vs. personal computers) make an impact on the students' learning behaviour during the learning activities?

\section{Research methodology}

To answer the above questions, this study adopted qualitative and quantitative approaches. A quasi-experiment was conducted to prove the differences in learning performance and behaviour patterns between students who used LMTs and those who used PCs to complete tasks in a game-based learning system.

The course adopted for this study, Electrical Science for the fifth grade, covered domestic electricity, series and parallel connections, an eco-friendly lifestyle based on electricity use, and electrical safety. This study designed the contents of the game-based learning system in line with the competence indicators of Nature and Science Technology for the fifth grade.

\section{Subjects}

Consisting of 49 Taipei elementary school fifth graders, all 11 and 12 years old, the study participants came from two classes taught by the same teacher. Because they begin to take training of computer courses from the third grade, they have basic information technology (IT) skills (such as Word, PowerPoint and PrintMagic) and Chinese input capability (25 words per second). One of the classes assigned as the experimental group used LMTs, while the other class assigned as the control group used personal computers. All of the participants in these two groups were divided into eight sub-groups, with 3 or 4 participants in each sub-group.

\section{Procedure}

The experiment lasted 7 weeks, from April 2011 to May 2011. Figure 2 shows the experimental procedure. All of the students took a pre-test at the beginning of the learning activity based on their knowledge of electrical science to measure their prior-knowledge levels of electrical science. The students were separated into two groups, experimental and control, to participate separately in a learning activity called the Tales of Phantasia by using various learning instruments (i.e. LMTs and personal computers). The experiment lasted for 4 weeks, with each week featuring a 40 minute experimental activity. Next, the overall activity during the student learning was recorded to analyse how the two groups differ in learning behaviour patterns. Upon completion of the learning activity, all of the students took a post-test to evaluate their learning performance after undertaking the learning activity and quantifying the range of their electrical science knowledge. The post-test differed from the pre-test in content. Ten days later all of the students took the same post-test (i.e. the delayed post-test) again to evaluate how retention 
affects academic achievement by calculating their learning retention.

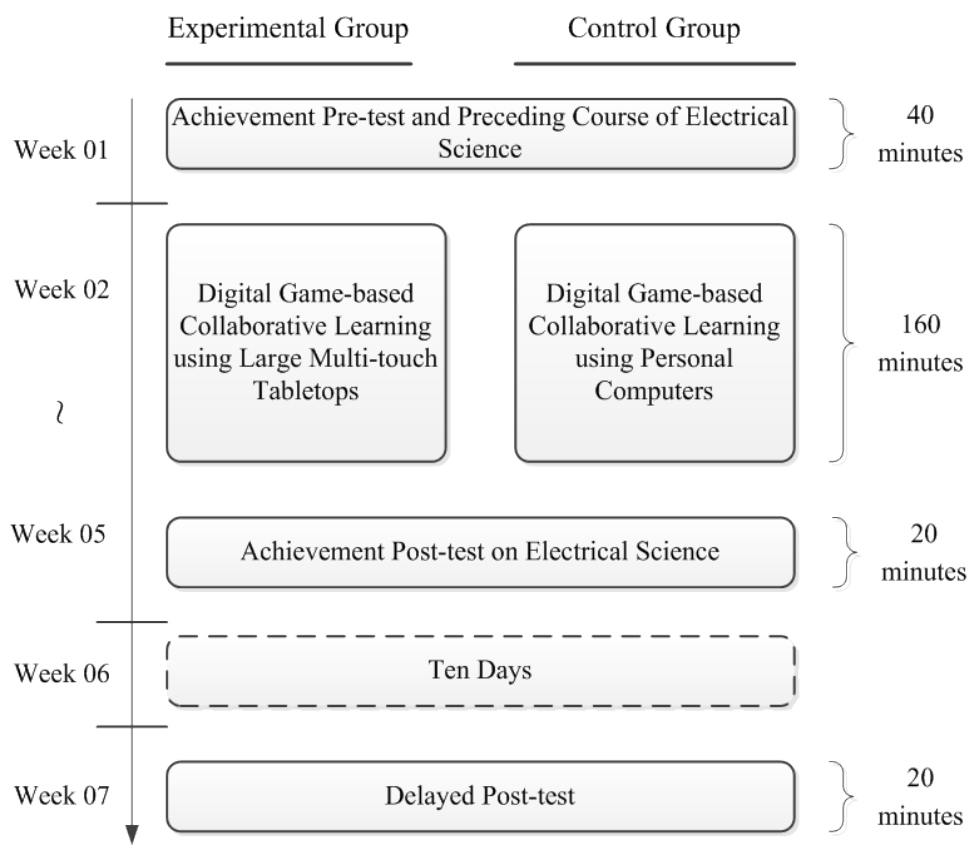

Figure 2. The procedure of the experiment

\section{Design of the learning activity}

The activity theory focuses on human practices associated with the development process, on both individual and social levels. In particular, the activity theory sheds light on how users utilises the tools to achieve the outcome through the interaction of its elements (i.e. tool, subject, and object) in an activity from a socio-cultural perspective (Tan \& Melles, 2010). Additionally the activity theory provides an ideal theoretical framework for examining how an educational game or resource mediates the players' understanding of other phenomena, while acknowledging the social and cultural contexts in which the game is played (Squire, 2002). Therefore, the learning activity (Figure 3) is designed based on the activity theory of Engeström (1987), which considers seven elements: subject, tools, object, community, rules, division, and outcome.

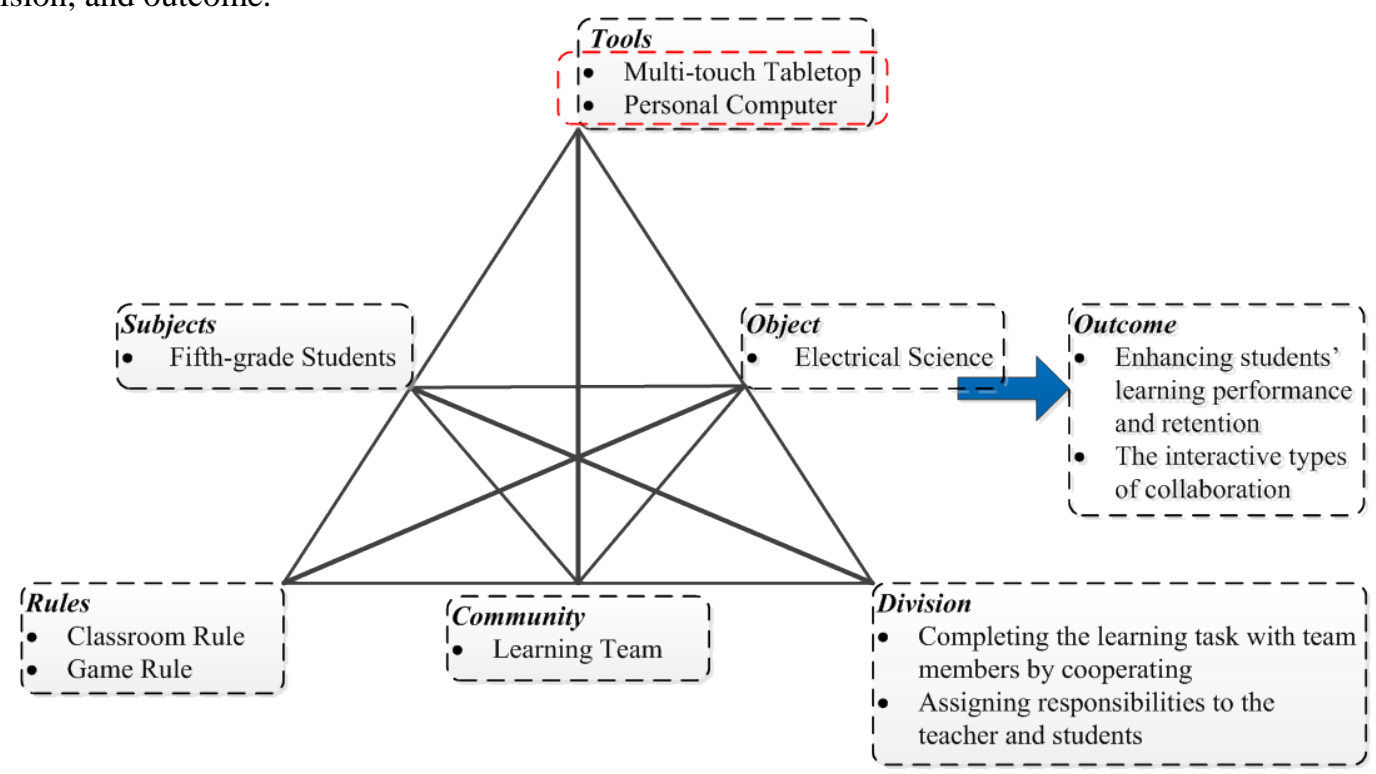

Figure 3. Activity design framework 
By using different learning instruments (i.e. LMTs and PCs) to complete the learning tasks of electrical science with team members, this study explored the different outcomes in learning performance and retention, as well as the interactive patterns of collaboration between these learning instruments. Table 1 describes applicability of the activity theory to particular collaborative learning types represented in the collaborative games on the LMTs and personal computers.

Table 1

Activity framework and description of elements

\section{Experimental Group}

\section{Control Group}

\begin{tabular}{|c|c|}
\hline Subject & $\begin{array}{l}\text { The students in this study were } 49 \text { fifth graders from an elementary school in Taipei; } \\
\text { the students were from two classes that were conducted by the same teacher. }\end{array}$ \\
\hline \multirow[t]{2}{*}{ Object } & The fifth-grade Electrical Science unit was chosen for the learning content and tasks. \\
\hline & $\begin{array}{l}\text { 1. 60-inch LMT developed by Nlighten } \\
\text { Inc., Ltd., Taiwan } \\
\text { 2. Digital game-based teaching activity, } \\
\text { which allowed more than one } \\
\text { participant to operate its system }\end{array}$ \\
\hline Rules & $\begin{array}{l}\begin{array}{l}\text { Participants were required to fulfill a } \\
\text { game task through } \\
\text { interaction. }\end{array} \\
\begin{array}{l}\text { face-to-face } \\
\text { his or her own personal computer to } \\
\text { fulfill a task through online discussion } \\
\text { and collaboration. }\end{array}\end{array}$ \\
\hline Community & 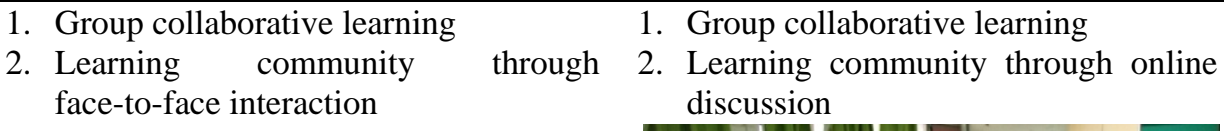 \\
\hline \multirow{3}{*}{$\begin{array}{l}\text { Division of } \\
\text { Labour }\end{array}$} & 1. Collaborative within a group \\
\hline & 2. Competition among groups \\
\hline & 3. Teacher as an assistant to provide hints when needed \\
\hline Outcome & $\begin{array}{l}\text { This activity was designed to enhance the participants' learning performance and } \\
\text { retention. }\end{array}$ \\
\hline
\end{tabular}

Digital game-based learning system

According to Prensky's (2012) concepts of human-computer interaction and social interaction, and Johnson and Johnson's (1991) collaboration by collaborating face-to-face interaction this study designed a digital game-based learning system called the Tales of Phantasia. Tales of Phantasia was installed on two learning instruments (i.e. LMTs and personal computers). For those using the LMTs, each team 
member stood around a LMT and solved game tasks via analysis and discussion with others in a co-located face-to-face collaborative learning environment (Figure 4(a)). Team members using personal computers operated their own computer to solve the game tasks via analysis and discussion with others in a game-based virtual learning environment (Fig. 4(b)).

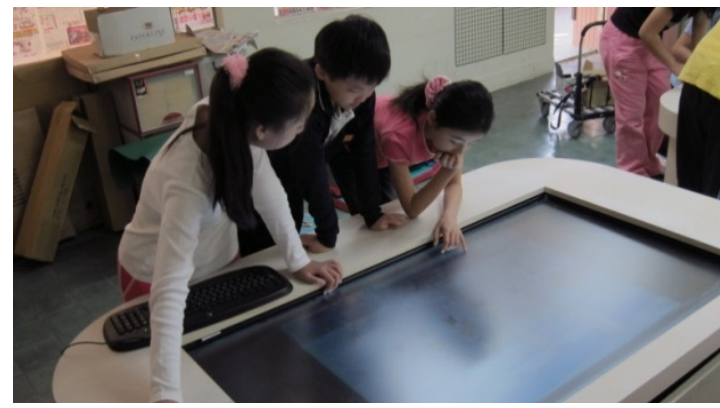

(a). The experimental group

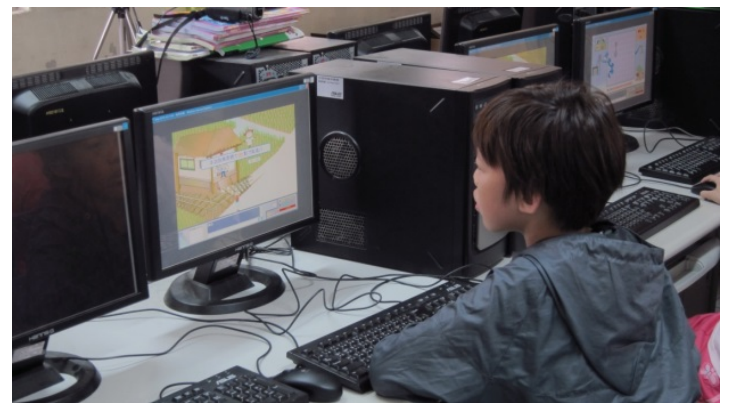

(b). The control group

Figure 4. Learning environments

The proposed system utilises a three-tier architecture of clients, application server, and database server, as illustrated in Fig. 5. In the client tier, a Flash Player allowed users to browse, operate, and manage the game functions. In the application server tier, the game was developed by Flash CS $5.5+$ ActionScript 3.0. The game included 15 sub-games (Table 1). The application server functioned in an intermediary role by connecting the client tier with the database tier. The synchronization of multi-users was implemented by Firefox Sync Server. In the database tier, the MS-SQL 2008 database consisted of a role database, map database, and gaming scenario database.

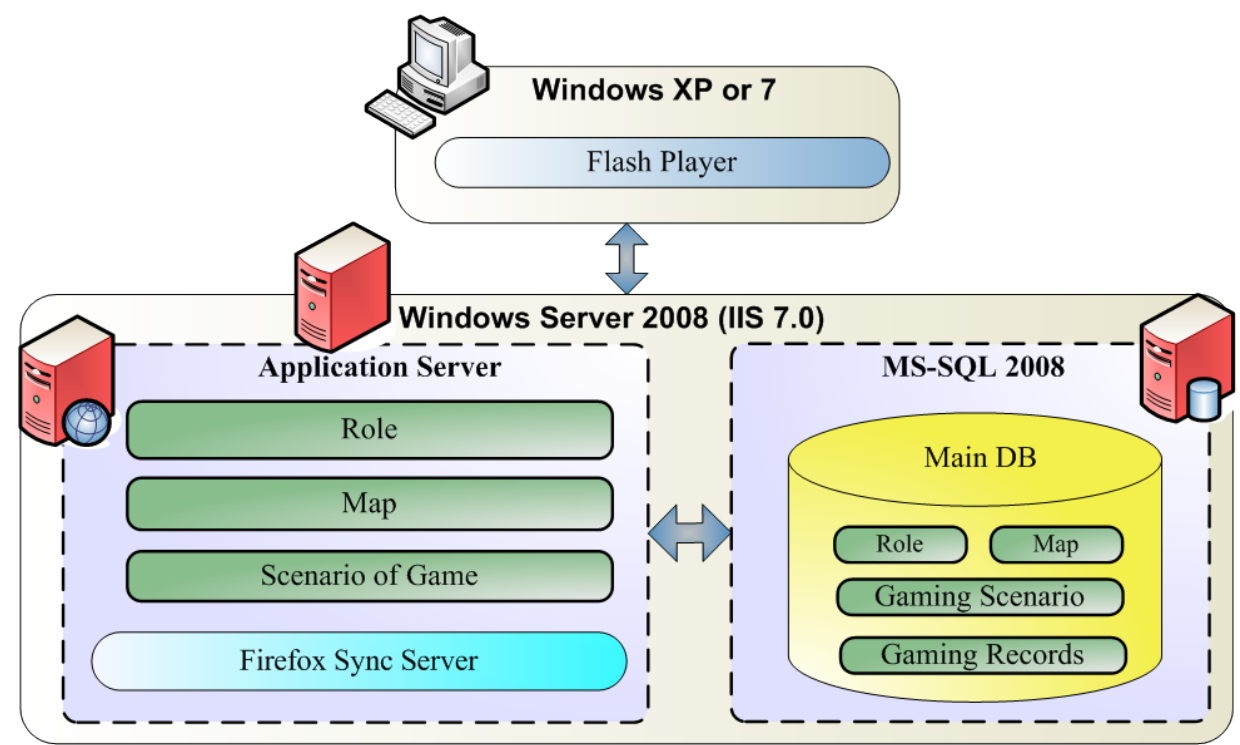

Figure 5. System architecture

Game design

The game-based learning system consisted of a role-playing game, and the design principle was based on the Cognitive-Affective Interaction Model of Williams. Upon completion of a learning task, players acquired expert knowledge and relative remuneration according to their behaviour while playing the game. Additionally, the players collaborated in small groups to solve or complete learning tasks, which fostered their ability to communicate and coordinate with peers and enhanced their team spirit and interpersonal relationships as well. This system designed 15 learning tasks based on different pedagogical strategies, which were assigned in different stages. Table 2 details the learning tasks as follows. 
Table 2

Description of the learning tasks

\begin{tabular}{|c|c|c|}
\hline Learning Task & $\begin{array}{l}\text { Teaching } \\
\text { Strategy } \\
\text { (Williams, } \\
\text { 1972) }\end{array}$ & Description \\
\hline \multicolumn{3}{|c|}{ Primitive Stage } \\
\hline $\begin{array}{l}\text { Classifying electrical } \\
\text { equipment }\end{array}$ & Attributes & $\begin{array}{l}\text { Students must judge whether the drawing represents } \\
\text { an electrical apparatus. }\end{array}$ \\
\hline \multicolumn{3}{|c|}{ Agricultural Stage } \\
\hline $\begin{array}{l}\text { Catching up with a } \\
\text { sparrow }\end{array}$ & $\begin{array}{l}\text { Evaluate } \\
\text { Situations }\end{array}$ & $\begin{array}{l}\text { Students must think effectively about how to catch up } \\
\text { with a sparrow, learning by trial and error. }\end{array}$ \\
\hline $\begin{array}{l}\text { Coming and going like a } \\
\text { shadow }\end{array}$ & Attributes & $\begin{array}{l}\text { Students must judge whether the thing that is held by a } \\
\text { mouse in a hole is a battery. }\end{array}$ \\
\hline Driving a cart & Attributes & $\begin{array}{l}\text { Students must decide whether the drawing represents a } \\
\text { conductor. }\end{array}$ \\
\hline $\begin{array}{l}\text { Rescuing electrical } \\
\text { equipment }\end{array}$ & Attributes & $\begin{array}{l}\text { Students must decide whether the thing in the water is } \\
\text { an electrical apparatus. }\end{array}$ \\
\hline $\begin{array}{l}\text { Looking for treasure in a } \\
\text { pit }\end{array}$ & $\begin{array}{l}\text { Tolerance for } \\
\text { Ambiguity }\end{array}$ & $\begin{array}{l}\text { Students must utilize the searchlight to find the } \\
\text { position of the colliery and utilize the shovel to } \\
\text { investigate the colliery. }\end{array}$ \\
\hline \multicolumn{3}{|r|}{ Industrial Stage } \\
\hline $\begin{array}{l}\text { Discarding the old and } \\
\text { welcoming the new }\end{array}$ & $\begin{array}{l}\text { Evaluate } \\
\text { Situations }\end{array}$ & $\begin{array}{l}\text { Students must change the old electric products into } \\
\text { energy-conserving products. }\end{array}$ \\
\hline $\begin{array}{l}\text { Comparing series } \\
\text { connections with parallel } \\
\text { connections }\end{array}$ & Analogies & $\begin{array}{l}\text { Students must link two pieces of similar circuitry from } \\
\text { sixteen circuit diagrams using their knowledge of } \\
\text { series connections and parallel connections. }\end{array}$ \\
\hline $\begin{array}{l}\text { Completing a jigsaw } \\
\text { puzzle }\end{array}$ & $\begin{array}{c}\text { Organized } \\
\text { Random Search }\end{array}$ & $\begin{array}{l}\text { Students must move the figure to the correct position, } \\
\text { which resembles a jigsaw puzzle in a 3-by-3 grid. }\end{array}$ \\
\hline Recycling resources & $\begin{array}{l}\text { Tolerance for } \\
\text { Ambiguity }\end{array}$ & $\begin{array}{l}\text { Students must retrieve old batteries that were } \\
\text { dispersed in different locations within a set time. }\end{array}$ \\
\hline Playing a Tetris-like game & $\begin{array}{l}\text { Adjustment to } \\
\text { Development }\end{array}$ & $\begin{array}{l}\text { This game is like Tetris. Students must connect a line } \\
\text { of more than three blocks of the same color. }\end{array}$ \\
\hline \multicolumn{3}{|c|}{ Information Stage } \\
\hline The trial of Gashapon & $\begin{array}{c}\text { Organized } \\
\text { Random Search }\end{array}$ & $\begin{array}{l}\text { Students must adjust things via rotation until the item } \\
\text { is correctly aligned with the objective figure. }\end{array}$ \\
\hline Finding out the truth & $\begin{array}{l}\text { Evaluate } \\
\text { Situations }\end{array}$ & $\begin{array}{l}\text { Students must find the wrong information according to } \\
\text { the situation provided by the system. }\end{array}$ \\
\hline Dodging dark clouds & $\begin{array}{l}\text { Adjustment to } \\
\text { Development }\end{array}$ & $\begin{array}{l}\text { Students must collect the badge of } \\
\text { energy-conservation and escape the obstruction of } \\
\text { black clouds by operating a solar car. }\end{array}$ \\
\hline $\begin{array}{l}\text { Who is the unfortunate } \\
\text { guy? }\end{array}$ & $\begin{array}{l}\text { Tolerance for } \\
\text { Ambiguity }\end{array}$ & $\begin{array}{l}\text { Students and the other three Non-Player Characters } \\
\text { (NPCs) must guess numbers in turn. Whoever guesses } \\
\text { the number designated by the system is the loser. }\end{array}$ \\
\hline
\end{tabular}

The system Interface

Each team member achieved the game tasks by identifying various clues, based on their knowledge of the task and discussion of these clues and knowledge, as shown in Figure 6(a). Electrical science-related knowledge and clues of the task were delivered using non-player characters (NPCs) (Figure 6(b)). Moreover, the students received a new gaming task from a NPC and obtained virtual coins according to their behaviour while playing the game. Additionally, to enhance their interest in the game, students could purchase clothes and accessories with their virtual coins. 


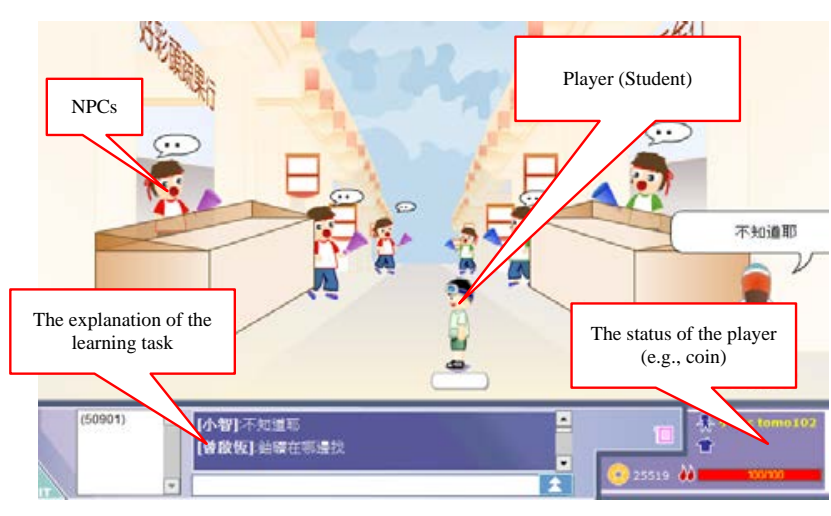

(a). Finding clues in the game

Figure 6. The tales of phantasia interface

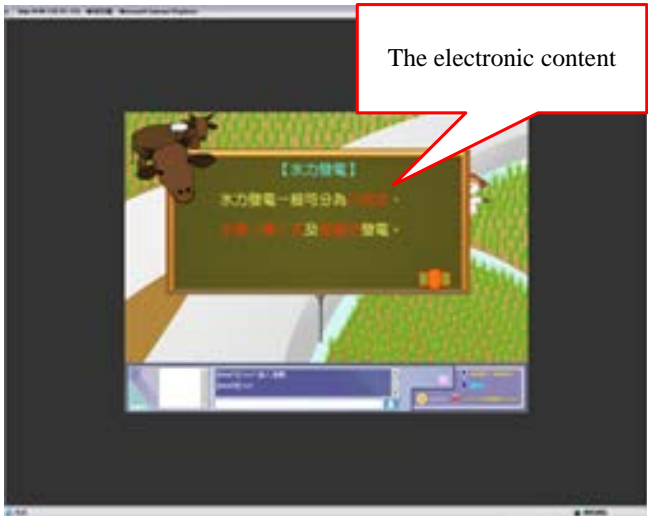

(b). Teaching content

\section{Research tools}

\section{Electrical science test}

The electrical science test in this study was designed by three Nature and Science Technology course instructors to evaluate the learning performance and memory retention of the participants. Range of the test was based on the fifth graders' competence indicators of electrical science in the Nature and Science Technology course, as established by the Ministry of Education in Taiwan. Following design of the test, drafts of the test were reviewed and edited by three professors with natural science and life technology backgrounds to verify and modify the appropriate statement of items, as well as construct expert validity.

Three separate tests were given to implement the experimental procedure and satisfy the research questions: the pre-test, post-test, and delayed post-test. The latter two tests shared the same items (i.e., the two tests differed in the pre-test). Because the students had not yet learned of electrical science before the experimental activity, the pre-test gave every student 25 multiple choice questions, which were designed to evaluate their prior-knowledge of electrical science: For example, "What is the general electrical voltage in Taiwan?" As for calculating the score for each question, students earned 4 points if they answered the question completely; the maximum score for each test was 100 points. As for reliability, the researcher adopted the internal consistency coefficient, obtaining $\alpha$ was .823 .

However, the two post-tests consisted of 40 multiple choice questions, including 10 from the pre-test and 30 from the contents of classroom and games. As for calculation of the score for each question, students earned 2.5 points if they answered the question completely; the maximum score for each test was 100 points. As for reliability of the test, the Cronbach $\alpha$ value was .781 .

\section{Behavioural indicators}

Behavioural indicators attempt to identify the students' interactive patterns of collaboration in various collaborative circumstances. By using a video camera, this study recorded the overall activity during the learning processes of students to analyze how these two groups differ in the interactive patterns of collaboration. Based on solicited high-quality helping behaviour from Webb and Farivar (1994) and Webb, Troper, and Fall (1995), this study designed six behaviour indicators for collaborative game-based learning, which were reviewed and modified by three professors with backgrounds in collaborative learning and education technology to demonstrate the feasibility and appropriateness of the indicators. Table 3 describes these indicators and the measurement criterion.

Based on the above behaviour indicators, the students' behaviours in the two groups were encoded according to the time sequence of behaviour conversion. For example, the encoded sequence was $\mathrm{Q} 2 \rightarrow \mathrm{Q} 3$ if a student discussed with other group members after reading learning task-related information. In the experimental group with eight teams, each team had approximately 255 behaviour conversions, resulting in 2,042 encoded sequences. In the control group with eight teams, each team had approximately 
225 behaviour conversions, resulting in 1,802 encoded sequences. This study randomly extracted 20 samples from each group to confirm inter-rater reliability. The Kappa=.64 (inter-rater reliability), resulting in a close correlation.

Table 3

Summary of positive learning behaviour and defined actions

\begin{tabular}{|c|c|c|}
\hline $\begin{array}{l}\text { Behaviour } \\
\text { Indicators }\end{array}$ & Description and Calculation Criterion & $\begin{array}{c}\text { Positive Learning } \\
\text { Behaviour Responses }\end{array}$ \\
\hline $\begin{array}{l}\text { Playing } \\
\text { Games (Q1) }\end{array}$ & $\begin{array}{l}\text { This indicator measured the activity related to playing the } \\
\text { game. To calculate this indicator, a single behaviour lasting } \\
30 \text { seconds earned one point each time. }\end{array}$ & $\begin{array}{l}\text { Gazing at screen } \\
\text { Operating the role of the } \\
\text { game }\end{array}$ \\
\hline $\begin{array}{l}\text { Reading } \\
\text { Information } \\
\text { (Q2) }\end{array}$ & $\begin{array}{l}\text { The participants obtained the electrical science materials by } \\
\text { talking with a NPC, which was regarded as the behaviour of } \\
\text { reading information. Calculating this indicator, a single } \\
\text { behaviour of reading information earned one point each } \\
\text { time. }\end{array}$ & Reading information \\
\hline $\begin{array}{l}\text { Group } \\
\text { Discussions } \\
\text { (Q3) }\end{array}$ & $\begin{array}{l}\text { The participants needed to collect and discuss the clues of } \\
\text { the learning tasks from different NPCs with other team } \\
\text { members when they attempted to complete the tasks of the } \\
\text { collaborative game. These collecting and discussing } \\
\text { behaviours were regarded as an important learning behaviour } \\
\text { indicator. Calculating this indicator, a single behaviour } \\
\text { continuing } 30 \text { seconds earned one point each time. }\end{array}$ & $\begin{array}{l}\text { Asking questions } \\
\text { Providing answers } \\
\text { Asking for information } \\
\text { Offering personal } \\
\text { interpretation } \\
\text { Making comments }\end{array}$ \\
\hline $\begin{array}{l}\text { Positive } \\
\text { Feedback } \\
\text { (Q4) }\end{array}$ & $\begin{array}{l}\text { This indicator measured positive feedback during the } \\
\text { learning activity; for example, participants praised team } \\
\text { members for their opinions presented. To calculate this } \\
\text { indicator, a single behaviour lasting } 30 \text { seconds earned one } \\
\text { point each time. The calculation criterion is that a single } \\
\text { behaviour of positive feedback earned one point each time. }\end{array}$ & $\begin{array}{l}\text { Encouraging teammates } \\
\text { Suggesting learning } \\
\text { direction } \\
\text { Responding to } \\
\text { teammates }\end{array}$ \\
\hline $\begin{array}{l}\text { Division of } \\
\text { Labour } \\
\text { (Q5) }\end{array}$ & $\begin{array}{l}\text { To solve the overall learning tasks, the team members needed } \\
\text { to assign different tasks to each member and to complete the } \\
\text { different tasks, respectively. The behaviour of assigning } \\
\text { work is regarded as the division of labour. Calculating this } \\
\text { indicator, a single behaviour continuing } 30 \text { seconds earned } \\
\text { one point each time. }\end{array}$ & $\begin{array}{l}\text { Collectively making } \\
\text { learning the object } \\
\text { Defining problems } \\
\text { Establishing work } \\
\text { procedures }\end{array}$ \\
\hline $\begin{array}{l}\text { Unrelated } \\
\text { to Learning } \\
\text { (Q6) }\end{array}$ & $\begin{array}{l}\text { This indicator measured any movement not related to the } \\
\text { learning process. The calculation criterion is that a single } \\
\text { behaviour lasting } 30 \text { seconds earned one point each time. }\end{array}$ & $\begin{array}{l}\text { Gossiping } \\
\text { Daydreaming }\end{array}$ \\
\hline
\end{tabular}

\section{Results}

Exactly how the collaborative games installed on both LMTs and PCs affect learning performance and behaviour was examined by paired-sample $t$-tests, analysis of covariates (ANCOVA), and sequential analysis. The significance level was set to 0.05. Learning performance on the achievement test of electrical science was collected, analyzed, and stated as follows.

\section{Analysis of collaborative games installed on different learning instruments: learning performance and memory retention}

Table 4 lists the mean scores for the tests of electrical science between the experimental and control groups. The experimental group scored higher $(\mathrm{m}=69.20$ and $\mathrm{m}=71.80)$ in the post-test and the delayed post-test than the control group did $(\mathrm{m}=63.58$ and $\mathrm{m}=61.62)$, whereas the control group scored higher $(m=59.79)$ than the experimental group did $(m=59.48)$ in the pre-test.

Calculation of a paired-samples $t$-test was performed to examine how the pre-test and the post-tests significantly differ from each other. According to the $t$-test results, the experimental group participants 
scored significantly higher in the post-test than in the pre-test $(t=4.364, p<.001)$, whereas the control group participants showed insignificant advancement $(t=1.584, p=.127)$. Moreover, the experimental group participants achieved a high quality of memory retention since the post-test and the delayed post-test did not significantly differ from each other $(t=1.086, p=.228)$

Table 4

The descriptive statistics of the study

\begin{tabular}{lccccccc}
\hline & \multirow{2}{*}{ Number } & \multicolumn{2}{c}{ Pre-test } & \multicolumn{2}{c}{ Post-test } & \multicolumn{2}{c}{ Delayed Post-test } \\
\cline { 7 - 9 } & Mean & SD & Mean & SD & Mean & SD \\
\hline Experimental & 25 & 59.48 & 14.34 & 69.20 & 11.39 & 71.80 & 11.15 \\
Group & 24 & 59.79 & 11.56 & 63.58 & 14.07 & 61.62 & 14.51 \\
Control Group & & & & & & &
\end{tabular}

Differences in learning performance

ANCOVA analysis was performed to investigate whether the experimental and control groups significantly differed in learning performance. During ANCOVA, an attempt was made to regulate how the pre-test and the learning approaches affect the post-test scores, in which the pre-test scores were considered the covariate; the post-test scores were considered the dependent variable; and each of the two learning approaches (i.e. LMTs and personal computers) were considered the fixed factor when confirming how the post-test scores and the two learning approaches are related.

The effect of the interaction between the pre-test and the learning approaches was in significant $(F=1.275$, $p=.265$ ) before the ANCOVA analysis. Analysis results indicated that the homogeneity assumption was not violated. Results of the ANCOVA analyses revealed a significant difference in the adjusted scores between usage of LMTs and PCs (Table 5). Learning performance of the electrical science test indicated the experimental group students learned more effectively than the control group ones did $(F=4.362$, $\left.p<0.05, \eta^{2}=0.087\right)$. Moreover, the effect size $\left(\eta^{2}=.087\right)$ was more than the one suggested by (Cohen, 1988) $\left(.138>\eta^{2} \geq .059\right)$, explaining the correlation between learning approaches and student learning performance.

Table 5

One-way analysis of covariance of electrical science achievement tests

\begin{tabular}{cccccc}
\hline Group & Number & $\begin{array}{c}\text { Adj-M } \\
\text { (Adjust-Means) }\end{array}$ & F-value & $\mathbf{R}^{2}$ (Adj R $\mathbf{R}^{\mathbf{}}$ ) & $\mathbf{\eta}^{2}$ \\
\hline Experimental group & 25 & 69.85 & & \\
Control group & 24 & 64.73 & $4.362^{*}$ & $.422(.397)$ & 0.087 \\
${ }^{*} \rho<0.05$ & & & &
\end{tabular}

\section{Differences in electrical science learning retention}

Learning, memory, and forgetting belong to the learning process (Slavin, 1994). Regarded as learning retention, memory is divided into sensory, short-term, and long-term. Based on the forgetting curve hypothesis of Ebbinghaus (1985), a meaningless message from teaching materials is retained at a percentage of $50 \%$ to $60 \%$ after 20 minutes, and 6 days later declines to $20 \%$. A meaningful learning approach is thus crucial in transforming short-term memory into long-term memory when learners attempt to acquire new knowledge.

With digital games in collaborative learning using multi-touch screens, learning retention can be improved through multimedia assistance, discussion through collaborative cooperation, and the behaviour of learning in which learned knowledge is applied in games. This section examines how to provide learners with meaningful messages in order to enhance their learning retention (i.e., delayed post-test).

Analysis of covariance was conducted to examine whether the control and experimental groups significantly differ at $p<.05$ on the post-test. During ANCOVA, an attempt was made to regulate how the 
post-test and the learning approaches affect the delayed post-test scores, in which the post-test scores were considered to be the covariate; the delayed post-test scores were considered to be the dependent variable, and the learning approaches were considered the fixed factor when examining how the delayed post-test scores and the learning approaches are related.

The homogeneity assumption was not violated. The pre-test and the learning approaches did not significantly differ in the homogeneity of regression coefficient $(F=2.824, p>0.05)$. Table 6 summarises the results of ANCOVA between the adjusted mean scores on the delayed post-test. According to the ANCOVA results, the experimental and control groups significantly differed in post-test scores $(F=4.800$, $\left.p<0.05, \eta^{2}=0.094\right)$. In addition, the effect size of the experiment reached a medium level $\left(\eta^{2}=.094\right)$. Analysis results indicated that the experimental group displayed a higher level of learning retention than the control group.

Table 6

One-way analysis of covariance of electrical science achievement tests (teaching approaches - learning retention)

\begin{tabular}{cccccc}
\hline Group & Number & $\begin{array}{c}\text { Adj-M } \\
\text { (Adjust-Means) }\end{array}$ & F-value & $\mathrm{R}^{2}$ (Adj R $\left.{ }^{2}\right)$ & $\eta^{2}$ \\
\hline Experimental group & 25 & 71.89 & $4.800^{*}$ & $.467(.444)$ & 0.094 \\
Control group & 24 & 61.53 & & & \\
${ }^{*} \rho<0.05$ & & &
\end{tabular}

\section{Learning behaviour patterns in the two groups}

As the above statistics results have demonstrated, the experimental group achieved a higher level of learning performance and retention than the control group did. However, to what extent the collaborative game influenced the learning performance and retention of the students depended on the learning instrument on which it was installed. By using sequential analysis (Bakeman \& Gottman, 1997), this study investigated how the two groups differ and conjecture on the reasons for such differences.

Encoding the two groups' learning behaviour from the video allowed us to obtain a frequency matrix of the experimental group. Moreover, an adjusted residuals table was constructed by undertaking sequential analysis to calculate the behaviour transfer matrix (Table 7). The rows represent the initial behaviour, and the columns represent the behaviours after the row's behaviour. A specific behaviour sequence is significant (e.g., Q1 $\rightarrow$ Q2) when the Z-score is higher than $1.96(p>0.05)$. According to this table, the significant sequences for the experimental group included the following: Q1 $\rightarrow Q 2, Q 1 \rightarrow Q 4, Q 1 \rightarrow Q 5$, $\mathrm{Q} 2 \rightarrow \mathrm{Q} 3, \mathrm{Q} 2 \rightarrow \mathrm{Q} 5, \mathrm{Q} 3 \rightarrow \mathrm{Q} 1, \mathrm{Q} 4 \rightarrow \mathrm{Q} 1, \mathrm{Q} 5 \rightarrow \mathrm{Q} 1, \mathrm{Q} 5 \rightarrow \mathrm{Q} 4$, and Q6 $\rightarrow \mathrm{Q} 1$. Moreover, the significant sequences for the control group included the following: Q1 $\rightarrow$ Q2, Q1 $\rightarrow$ Q6, Q2 $\rightarrow$ Q1, Q2 $\rightarrow$ Q3, Q3 $\rightarrow$ Q1, $\mathrm{Q} 4 \rightarrow \mathrm{Q} 1, \mathrm{Q} 5 \rightarrow \mathrm{Q} 3, \mathrm{Q} 5 \rightarrow \mathrm{Q} 6$, and Q6 $\rightarrow \mathrm{Q} 1$.

Table 7

Adjusted residuals table

\begin{tabular}{|c|c|c|c|c|c|c|c|}
\hline & & Q1 & Q2 & Q3 & Q4 & Q5 & Q6 \\
\hline \multirow{6}{*}{$\frac{\text { Experimental }}{\text { Group }}$} & Q1 & -16.59 & 21.89* & -5.00 & 3.69* & $2.48 *$ & 1.37 \\
\hline & Q2 & -3.06 & -11.25 & 16.95* & -3.52 & $6.00 *$ & -1.31 \\
\hline & Q3 & $14.72 *$ & -7.09 & -7.89 & -0.10 & -3.50 & -1.45 \\
\hline & Q4 & 9.08* & -5.50 & -2.45 & -3.42 & -2.06 & 1.30 \\
\hline & Q5 & 6.83* & -5.36 & -1.19 & $2.66^{*}$ & -4.81 & 1.35 \\
\hline & Q6 & $5.72 *$ & -3.09 & -2.15 & 0.24 & -2.23 & -1.04 \\
\hline \multirow{6}{*}{$\frac{\text { Control }}{\text { Group }}$} & Q1 & -19.60 & 20.03* & 0.68 & 1.80 & 1.21 & $6.37 *$ \\
\hline & Q2 & $12.58 *$ & $\begin{array}{l}-13.58 \\
\end{array}$ & $2.28 *$ & 0.40 & 1.30 & -3.61 \\
\hline & Q3 & $8.40 *$ & -5.66 & -3.68 & -1.27 & -1.75 & -3.88 \\
\hline & Q4 & $4.20 *$ & -3.42 & 0.39 & -0.90 & -0.86 & -1.92 \\
\hline & Q5 & 1.46 & -3.29 & $2.27 *$ & -0.86 & -0.83 & 1.97* \\
\hline & Q6 & $9.46^{*}$ & -6.68 & -3.88 & -1.92 & -1.84 & -2.13 \\
\hline
\end{tabular}

* Z>1.96 
The diagram of behaviour transfer (Figure 7) was drawn according to the significant sequences in Table 7. The directional arrows in the diagram denote the directions of behaviour transfer, and their width represents the level of significance. Figure 7 illustrates the patterns of behaviour transfer in the overall collaborative learning process (EQ behalf to experimental group Q and CQ behalf to control group Q).

Figure 7(a) displays the experimental group's diagram of behaviour transfer, in which there are two cyclical learning patterns. As a continuously collaborating process, a cyclical learning pattern must contain three or more behaviour transfers; in addition, only two behaviour transfers between two behaviour indicators (e.g., Q1 $\rightarrow$ Q2 and Q2 $\rightarrow$ Q1) are regarded as a cyclical learning pattern. The diagram of behaviour transfer includes three main cyclical learning patterns.

First, the sequences of playing games to reading information $(\mathrm{Q} 1 \rightarrow \mathrm{Q} 2, \mathrm{Z}=21.89)$, reading information to group discussions (EQ2 $\rightarrow \mathrm{EQ} 3, \mathrm{Z}=16.95$ ), and group discussions to playing games (EQ3 $\rightarrow \mathrm{EQ} 1, \mathrm{Z}=14.72$ ) were the main behaviour sequences when solving the tasks in the collaborative game, resulting in a discussing cyclical learning pattern. Second, the sequences of playing games to reading information $(\mathrm{EQ} 1 \rightarrow \mathrm{EQ} 2, \mathrm{Z}=21.89$ ), reading information to division of labour (EQ2 $\rightarrow \mathrm{EQ} 5, \mathrm{Z}=6.00)$, and division of labour to playing games $(\mathrm{Q} 5 \rightarrow \mathrm{Q} 1, \mathrm{Z}=6.83)$ formed a division of labour cyclical learning pattern. Third, a collaborative playing cyclical learning pattern consisted of the sequences of playing games to reading information ( $E Q 1 \rightarrow E Q 2, Z=21.89$ ), reading information to division of labour (EQ2 $\rightarrow E Q 5, Z=6.00$ ), division of labour to positive feedback (EQ5 $\rightarrow \mathrm{EQ} 4, \mathrm{Z}=2.66$ ), and positive feedback to playing games $(\mathrm{EQ} 4 \rightarrow \mathrm{EQ} 1, \mathrm{Z}=9.08)$.

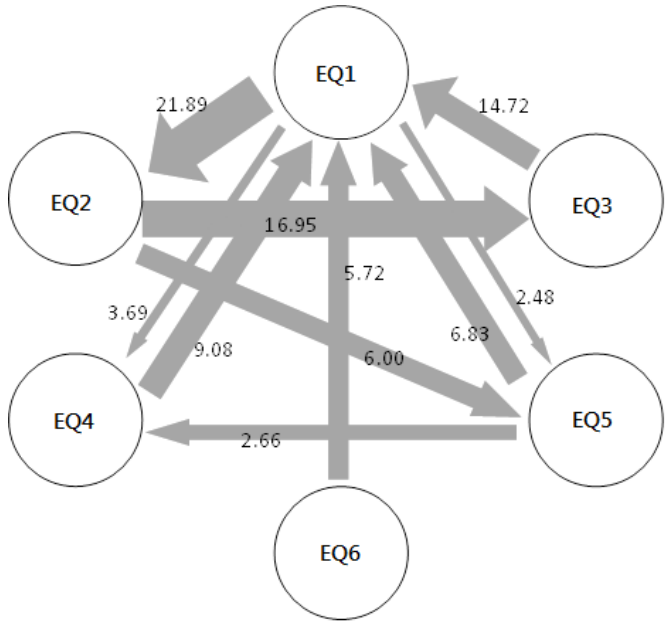

(a) Experimental group

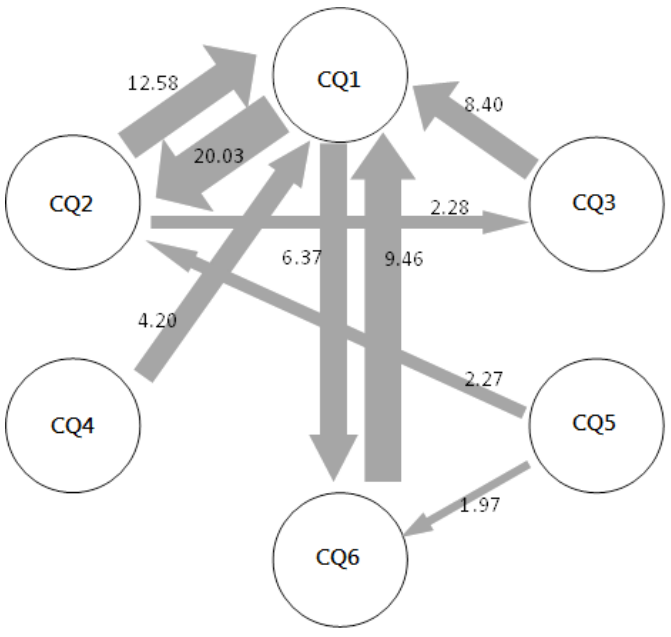

(b) Control group

Figure 7. Diagram of behaviour transfer

Correspondingly, the sequences of EQ1(playing games) $\rightarrow$ EQ5(division of labour), EQ5 $\rightarrow$ EQ4(positive feedback), and EQ4 $\rightarrow$ EQ1 closely resembled the collaborative playing cyclical learning pattern. From the above discussion, playing games were initiated. How to complete the game tasks was then proposed, during which division of labour assisted the learning processes that proposed solutions or collected information.

Figure 7(b) presents all of the sequences of the control group in Table 7 that reached a level of significance. The diagram of behaviour transfer had only one main cyclical learning pattern, i.e. discussing cyclical learning pattern, which is the sequences of playing games to reading information $(\mathrm{CQ} 1 \rightarrow \mathrm{CQ} 2, \mathrm{Z}=20.03$ ), reading information to group discussions (CQ2 $\rightarrow \mathrm{CQ} 3, \mathrm{Z}=2.28$ ), and group discussions to playing games $(\mathrm{CQ} 3 \rightarrow \mathrm{CQ} 1, \mathrm{Z}=8.40)$. Correspondingly, playing games was an initial learning behaviour, yet resulted in two single cyclical learning patterns. One of the cyclical learning patterns was CQ1 $\rightarrow$ CQ2 $(Z=20.03)$ and $C Q 2 \rightarrow C Q 1(Z=12.58)$; the other was CQ1 $\rightarrow$ CQ6 $(Z=6.37)$ and

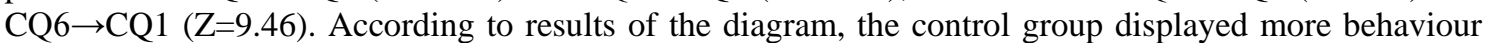
transfer of distraction than the experimental group did. For instance, they were easily distracted in play games (CQ1 $\rightarrow$ CQ6, Z=6.37) and division of labour (CQ5 $\rightarrow$ CQ6, Z=1.97). 


\section{Discussion}

The differences in learning approaches could have affected the difference in learning performance and retention. Results of this study indicated that the experimental group experienced significant growth in both their learning performance and retention, indicating that the students who used LMTs more significantly improved than those who used personal computers (Table 4). We can infer from the learning behaviour patterns that using LMTs as a learning tool has many advantages. For example, learners' behaviour towards collaborative learning more than when using PCs. Student in the experimental group functioned in the role of both a narrator and a partner who collaborated with their classmates during the playing process when using LMTs to achieve tasks in the game-based learning system. Moreover, through a co-located face-to-face collaborative environment, the collaborative partners can provide immediate feedback during learning activities when students ask questions (Clayphan, Collins, Ackad, Kummerfeld, \& Kay, 2011; Higgins et al., 2011). Furthermore, students can identify their wrongs while studying, thus providing them with an opportunity to re-learn the material (Cortez et al., 2009).

The digital game-based learning system could capture students' concentration and enhance their interest in learning, ultimately improving their academic achievement. However, several behaviours unrelated to learning (e.g., gossiping or daydreaming) could negatively impact their academic achievement. Unlike the experimental group, the control group lacked immediate feedback during learning activities through a co-located face-to-face collaborative environment when students ask questions. We can thus infer that the progress range in academic achievement for the control group was less than for the experimental group.

Several studies (e.g., Dale, 1969; Mayer, 1991; Stice, 1987) found that features of co-work (e.g., discussion and practice) enhance learning performance and memory retention through learning by doing, with various channels available to store messages. LMTs have similar features, which facilitated collaborative learning activities for learners unconstrained by obtrusive technologies, rather than mediated interactions during a brainstorming activity such as mixed discussions, collaboration, and competitive activities (Chaboissier, Isenberg, \& Vernier, 2011; Gross, Fetter, \& Liebsch, 2008), and parent-young child interactions (Xiao \& Martin, 2012). Results of this study further proved that the use of LMT technology by the experimental group participants improved communication with other peers, as well as the learning process and co-work activities during the brainstorming activity.

Above results resembled those in previous studies that asserted that LMTs have the potential to provide innovative ways to support collaborative learning, and more specifically facilitate individuals in more effective collaborative learning (Clayphan et al., 2011; Mart, Collins, Kay, \& Yacef, 2011; Morris, Lombardo, \& Wigdor, 2010). Moreover LMTs can improve student performance, reduce workload, and increase enjoyment (Shaer et al., 2011). These attributes were evident in this study, where the experimental group participated in the collaborative learning activity in a co-located face-to-face collaborative environment using LMTs. Consequently, students have more opportunities to allot assignments in order to share information, and discuss solutions and reinforce the diversification of cyclical learning patterns. However, the cyclical learning patterns were weaker for the online teams using PCs than for those using LMTs.

Many studies have contended that collaborative learning can positively influence learning performance (Janssen, Erkens, Kirschner, \& Kanselaar, 2010; Slavin, 1990), encourage mutual concern among students (Slavin, 1980), and nurture the development of knowledge construction (Mizuno, 2011). The behaviour observed in this study demonstrates that the participants using LMTs tended to focus on meaningful learning behaviour than those using personal computers. The frequency of behaviour that was unrelated to learning occurred 48 times in the experimental group and 177 times in the control group. Additionally, the transfer diagrams (Fig. 7) also reveal that engaging in meaningful learning behaviour was easier for the experimental group than it was for the control group. This difference is partially owing to that LMTs offered participants with more face-to-face interaction, allowing them to more actively engage in completing the game tasks by gathering information separately and engaging in discussions as a collaboratively. According to Tse, Greenberg, Shen, \& Forlines (2006), the success of collaboration depends on a common view, multi-user direct input, mutual monitoring of others' activities, as well as verbal and gestural utterances. Consequently, learning behaviour of the experimental group resulted in more meaningful learning and better overall learning performances than that of the control group. 
Students enrolled in a face-to-face course had a more favorable opinion of the amount and type of interactions among the students (Johnson, Aragon, Shaik, \& Palma-Rivas, 2000) than online collaboration and discussion. According to the behaviour transfer results, the experimental group achieved better behaviour transfers and diversified cyclical learning patterns than control group. For example, the behaviour transfer from reading information to group discussions in the experimental group (EQ2 to EQ3) was achieved 238 times, while it was achieved 63 times in the control group (CQ2 to CQ3). Moreover, the levels of significance for the experimental group were higher than those for the control group. Analysis results indicated those experimental group members were inclined to actively engage in group discussions when solving problems after reading the information. Control group members engaged in group discussions as well, yet tended to play games after reading the questions. We thus conclude that LMTs with digital game-based collaborative learning systems as a collaborative learning tool are invaluable in increasing students' interactive patterns in learning activity.

Sun and Lin (2004) asserted that the division of labour is a major element of collaborative learning. Collaboration includes division of labour, the parallel independent solution of subtasks, and a combination of individual contributions in a joint product (Rummel \& Spada, 2005). Each group member is responsible for searching for one clue. All the members then work together to incorporate individual contributions into the final outcome. For example, in this study, the behaviour transfer frequency of the division of labour in the experimental group was achieved 157 times while it was achieved 39 times in the control group. Participants in the experimental group tended to divide labour after reading information; they then searched for clues in the game after group discussions. Analysis results indicated that students using LMTs appeared to be more efficient at working together than the students using personal computers.

\section{Conclusions}

This research proved the effectiveness of LMTs as a collaborative learning platform, in which multiple students play together using a digital surface. Moreover, by bridging the gap between digital game-based learning and collaborative learning, this study provides evidence of novel and engaging experiences when using a multi-player, multi-modal tabletop display.

\section{Contribution}

A multi-touch tabletop collaborative game was developed as a multi-user learning console to facilitate co-located collaborative learning of the students. This study also added a series of learning activities based on the six elements found in the activity theory (i.e. subject, tools, object, rules, community, and division of labour) to assist students in completing the tasks through team collaboration. Integrating these learning elements with face-to-face team cooperation offered the students with quality learning interaction and enhanced their learning performance and retention. For instance, students first played the collaborative game (tools) and obtained a problem involving electrical science (object). The students then discussed with team members (i.e. community) and searched for clues from NPCs through division of labour (i.e. division of labour), and then solved the problem (i.e. outcome). Therefore, we posit that students can acquire more knowledge and enhance their learning retention than playing and learning alone when a game allows them to participate in more interactions and discussions about learning.

\section{Future work and limitations}

Based on the above conclusions, we recommend the following two areas for future research. First, the experimental scale must be broadened to make the results more representative. Digital game-based collaborative learning with large multi-touch screens proved to be helpful to both learning performance and memory retention. However, owing to the small scale of the experiment, the results are limited. The scale of the experiments must be extended to develop teaching integrated information technologies. Second, multi-touch tabletop collaborative games should be applied to different subjects. Electrical science and technology at the elementary school level was targeted in this collaborative learning study. Other subjects, including math and English at the junior high or senior high level, could be targeted for related teaching and learning. 
Several limitations of this study are important to note. First, the research covered a relatively short term (7 weeks). A longitudinal design would be useful in assessing the cumulative effects of different learning devices on the students' learning performance over time. Second, the experimental activities are attributable to exploratory and small-scale test experiment. The results were difficult to infer to that all Taiwan's elementary school students will enhance their learning performance and increase interaction among peers.

\section{Acknowledgments}

This research is partially supported by the "Aim for the Top University Project” and "Center of Learning Technology for Chinese” of National Taiwan Normal University (NTNU), sponsored by the Ministry of Education, Taiwan, R.O.C. and the "International Research-Intensive Center of Excellence Program" of NTNU and Ministry of Science and Technology, Taiwan, R.O.C. under Grant no. NSC 103-2911-I-003-301, 103-2622-S-003-001,103-2511-S-003-051-MY3,101-2511-S-003-056-MY3

\section{References}

Antle, A. N., Bevans, A., Tanenbaum, J., Seaborn, K., \& Wang, S. (2011, January). Futura: Design for collaborative learning and game play on a multi-touch digital tabletop. Paper presented at the Fifth International Conference on Tangible, Embedded, and Embodied Interaction, Funchal, Portugal.

Bakeman, R., \& Gottman, J. M. (1997). Observing interaction: an introduction to sequential analysis. New York: Cambridge University Press.

Baltra, A. (1990). Language learning through computer adventure games. Simulation \& Gaming, 21(4), 445-452.

Chaboissier, J., Isenberg, T., \& Vernier, F. E. E. (2011, January). RealTimeChess: Lessons from a participatory design process for a collaborative multi-touch, multi-user game. Paper presented at the ACM International Conference on Interactive Tabletops and Surfaces, Kobe, Japan.

Chang, Y. C., Peng, H. Y., \& Chao, H. C. (2009). Examining the effects of learning motivation and of course design in an instructional simulation game. Interactive Learning Environments, 18(4), 319-339. doi: 10.1080/10494820802574270

Chen, T.-S., Chang, C.-S., Lin, J.-S., \& Yu, H.-L. (2009). Context-aware writing in ubiquitous learning environments. Research and Practice in Technology Enhanced Learning, 4(1), 61-82.

Chiang, I. T., Shih, R.-C., Liu, E.-F., \& Lee, A.-Y. (2011). Using Game-Based Learning and Interactive Peer Assessment to Improve Career Goals and Objectives for College Students. In M. Chang, W.-Y. Hwang, M.-P. Chen \& W. Müller (Eds.), Edutainment Technologies. Educational Games and Virtual Reality/Augmented Reality Applications (Vol. 6872, pp. 507-511): Springer Berlin Heidelberg.

Clayphan, A., Collins, A., Ackad, C., Kummerfeld, B., \& Kay, J. (2011, January). Firestorm: A brainstorming application for collaborative group work at tabletops. Paper presented at the ACM International Conference on Interactive Tabletops and Surfaces, Kobe, Japan.

Cohen, J. (1988). Statistical power analysis for the behavioral sciences. Hillsdale, NJ, US: Lawrence Erlbaum.

Cortez, C., Nussbaum, M., Woywood, G., \& Aravena, R. (2009). Learning to collaborate by collaborating: a face-to-face collaborative activity for measuring and learning basics about teamwork1. Journal of Computer Assisted Learning, 25(2), 126-142. doi: 10.1111/j.1365-2729.2008.00298.x

Csikszentmihalyi, M. (1975). Beyond boredom and anxiety. San Francisco: Jossey-Bass.

Csikszentmihalyi, M. (1991). Flow: The psychology of optimal experience. New York: Harper Perennial.

Dale, E. (1969). Audio-visual methods in teaching (3rd ed.). New York: Holt.

Ebbinghaus, H. (1985). Memory: A contribution to experimental psychology. New York: Dover Publications.

Engestro“m, Y. (1987). Learning by Expanding: An Activity-theoretical Approach to Developmental Research. Orienta-Konsultit: Helsinki.

Eow, Y. L., \& Baki, R. (2010). Computer games development and appreciative learning approach in enhancing students' creative perception. Computers \& Education, 54(1), 146-161.

Goh, W. B., Shou, W., Tan, J., \& Lum, G. T. (2012, May). Interaction design patterns for multi-touch tabletop collaborative games. Paper presented at the CHI'12 Extended Abstracts on Human Factors in Computing Systems (pp. 141-150), Austin, Texas, USA.

Gross, T., Fetter, M., \& Liebsch, S. (2008, April). The cuetable: cooperative and competitive multi-touch interaction on a tabletop. Paper presented at the CHI'08 extended abstracts on Human factors in 
computing systems (pp. 3465-3470), Florence, Italy.

Higgins, S., Mercier, E., Burd, E., \& Hatch, A. (2011). Multi-touch tables and the relationship with collaborative classroom pedagogies: A synthetic review. International Journal of Computer-Supported Collaborative Learning, 6(4), 515-538. doi: 10.1007/s11412-011-9131-y

Huizenga, J., Admiraal, W., Akkerman, S., \& Dam, G. t. (2009). Mobile game-based learning in secondary education: engagement, motivation and learning in a mobile city game. Journal of Computer Assisted Learning, 25, 332-344.

Hung, C.-Y., Chang, T.-W., Yu, P.-T., \& Cheng, P.-J. (2012, March). The problem solving skills and learning performance in learning multi-touch interactive jigsaw game using digital scaffolds. Paper presented at the 2012 IEEE Fourth International Conference on Digital Game and Intelligent Toy Enhanced Learning (DIGITEL), Takamatsu, Japan.

Janssen, J., Erkens, G., Kirschner, P. A., \& Kanselaar, G. (2010). Effects of representational guidance during computer-supported collaborative learning. Instructional Science, 38(1), 59-88.

Johnson, D., \& Johnson, R. (1991). Learning together and alone. Englewood Cliffs, NJ: Prentice Hall.

Johnson, S. D., Aragon, S. R., Shaik, N., \& Palma-Rivas, N. (2000). Comparative analysis of learner satisfaction and learning outcomes in online and face-to-face learning environments. Journal of Interactive Learning Research, 11(1), 29-49.

Kiili, K. (2005). Digital game-based learning: Towards an experiential gaming model. The Internet and Higher Education, 8(1), 13-24. doi: http://dx.doi.org/10.1016/j.iheduc.2004.12.001

Liu, C. C., \& Kao, L. C. (2007). Do handheld devices facilitate face-to-face collaboration? Handheld devices with large shared display groupware to facilitate group interactions. Journal of Computer Assisted Learning, 23(4), 285-299. doi: 10.1111/j.1365-2729.2007.00234.x

Liu, T.-Y., \& Chu, Y.-L. (2010). Using ubiquitous games in an English listening and speaking course: Impact on learning outcomes and motivation. Computers \& Education, 555, 630-643.

Malone, T. (1981). What makes computer games fun? SIGSOC Bull., 13(2-3), 143. doi: $10.1145 / 1015579.810990$

Mart, R., Collins, A., Kay, J., \& Yacef, K. (2011, November). Who did what? Who said that?: Collaid: an environment for capturing traces of collaborative learning at the tabletop. Paper presented at the ACM International Conference on Interactive Tabletops and Surfaces, Kobe, Japan.

Mayer, R. E. (1991). Multimedia learning. New York: Cambridge University.

Mitchell, A., \& Savill-Smith, C. (2004). The use of computer and video games for learning - a review of the literature. London: Learning and Skills Development Agency.

Mizuno, M. (2011). Cooperative learning for rostering knowledge construction in Japanese high school. In C. W. N. Popov, M. Mihova \& J. Ogunleye (Eds.), Comparative education in teacher training, education policy, social inclusion, history of education (Vol. 19, pp. 119-124). Sofia: Bulgarian Comparative Education Society \& Bureau for Educational Services.

Morris, M. R., Lombardo, J., \& Wigdor, D. (2010, February). WeSearch: Supporting collaborative search and sensemaking on a tabletop display. Paper presented at the 2010 ACM Conference on Computer Supported Cooperative Work, Savannah, Georgia, USA.

Papastergiou, M. (2009). Digital game-based learning in high school computer science education: Impact on educational effectiveness and student motivation. Computers \& Education, 52(1), 1-12. doi: 10.1016/j.compedu.2008.06.004

Pinelle, D., Gutwin, C., \& Greenberg, S. (2003). Task analysis for groupware usability evaluation: Modeling shared-workspace tasks with the mechanics of collaboration. ACM Transactions on Computer-Human Interaction (TOCHI), 10(4), 281-311. doi: 10.1145/966930.966932

Piper, A. M., O'Brien, E., Morris, M. R., \& Winograd, T. (2006, November). SIDES: a cooperative tabletop computer game for social skills development. Paper presented at the 2006 20th Anniversary Conference on Computer Supported Cooperative Work, Banff, Alberta, Canada.

Prensky, M. (2007). Digital game-based learning. New York: McGraw-Hill.

Puntambekar, S. (2006). Analyzing collaborative interactions: divergence, shared understanding and construction of knowledge. Computers \& Education, 47(3), 332-351. doi: 10.1016/j.compedu.2004.10.012

Quigley, A., Subramanian, S., \& Izadi, S. (2009). Special issue on interaction with coupled and public displays. Personal and Ubiquitous Computing, 13(8), 549-550. doi: 10.1007/s00779-009-0242-7

Rick, J., Harris, A., Marshall, P., Fleck, R., Yuill, N., \& Rogers, Y. (2009, June). Children designing together on a multi-touch tabletop: an analysis of spatial orientation and user interactions. Paper presented at the 8th International Conference on Interaction Design and Children, Como, Italy.

Rick, J., Rogers, Y., Haig, C., \& Yuill, N. (2009). Learning by doing with shareable interfaces. Children, 
Youth and Environments, 19(1), 321-342.

Roblyer, M. D. (2003). Integrating educational technology into teaching (3rd ed.). Columbus, OH: Merrill Prentice Hall.

Rummel, N., \& Spada, H. (2005). Learning to collaborate: An instructional approach to promoting collaborative problem solving in computer-mediated settings. Journal of the Learning Sciences, 14(2), 201-241. doi: 10.1207/s15327809jls1402_2

Scardamalia, M. (2002). Collective cognitive responsibility for the advancement of knowledge. In B. Smith (Ed.), Liberal education in a knowledge society (pp. 67-98). Chicago: Open Court.

Schubert, M., George, S., \& Serna, A. (2012). Exploring the potential of tabletops for collaborative learning intelligent tutoring systems. In S. Cerri, W. Clancey, G. Papadourakis \& K. Panourgia (Eds.), Intelligent Tutoring Systems (Vol. 7315, pp. 632-633): Springer Berlin Heidelberg.

Scott, S. D., Mandryk, R. L., \& Inkpen, K. M. (2003). Understanding children's collaborative interactions in shared environments. Journal of Computer Assisted Learning, 19(2), 220-228. doi: 10.1046/j.0266-4909.2003.00022.x

Shaer, O., Strait, M., Valdes, C., Feng, T., Lintz, M., \& Wang, H. (2011). Enhancing genomic learning through tabletop interaction. Paper presented at the Proceedings of the 2011 annual conference on Human factors in computing systems, Vancouver, BC, Canada.

Shin, N., Sutherland, L. M., Norris, C. A., \& Soloway, E. (2012). Effects of game technology on elementary student learning in mathematics. British Journal of Educational Technology, 43(4), 540-560. doi: 10.1111/j.1467-8535.2011.01197.x

Slavin, R. E. (1980). Cooperative Learning. Review of Educational Research, 50(2), 315-342. doi: 10.3102/00346543050002315

Slavin, R. E. (1990). Cooperative learning: Theory, research, and practive. Needham Heights, MA: Allyn \& Bacon.

Slavin, R. E. (1994). Educational psychology: Theory and practice. Boston: Allyn and Bacon.

Squire, K. (2002). Cultural framing of computer/video games. Game studies, 2(1), 90, Retrieved from http://www.gamestudies.org/0102/squire/

Stanton, D., \& Neale, H. R. (2003). The effects of multiple mice on children's talk and interaction. Journal of Computer Assisted Learning, 19(2), 229-238. doi: 10.1046/j.0266-4909.2003.00023.x

Stice, J. E. (1987). Using Kolb's learning cycle to improve student learning. Enginering education, 77(2), 291-296.

Sun, C.-T., \& Lin, S. S. J. (2004). CORAL-View: A network based design environment for collaborative learning. International Journal of Instructional Media, 31(2), 151-166.

Sung, H.-Y., \& Hwang, G. J. (2013). A collaborative game-based learning approach to improving students' learning performance in science courses. Computers \& Education, 63(0), 43-51. doi: http://dx.doi.org/10.1016/j.compedu.2012.11.019

Tan, S., \& Melles, G. (2010). An activity theory focused case study of graphic designers' tool-mediated activities during the conceptual design phase. Design Studies, 31(5), 461-478. doi: 10.1016/j.destud.2010.05.002

Tse, E., Greenberg, S., Shen, C., \& Forlines, C. (2006). Multimodal multiplayer tabletop gaming. Mitsubishi Electric Research Laboratories. Retrieved from http://www.merl.com/reports/docs/TR2006-009.pdf

Tüzün, H., Yılmaz-Soylu, M., Karakuş, T., İnal, Y., \& Kızılkaya, G. (2009). The effects of computer games on primary school students' achievement and motivation in geography learning. Computers \& Education, 52(1), 68-77. doi: 10.1016/j.compedu.2008.06.008

Wang, L. C., \& Chen, M. P. (2010). The effects of game strategy and preference-matching on flow experience and programming performance in game-based learning. Innovations in Education and Teaching International, 47(1), 39-52. doi: 10.1080/14703290903525838

Webb, N. M., \& Farivar, S. (1994). Promoting helping behavior in cooperative small groups in middle school mathematics. American Educational Research Journal, 31(2), 369-395. doi: 10.3102/00028312031002369

Webb, N. M., Troper, J. D., \& Fall, R. (1995). Constructive activity and learning in collaborative small groups. Journal of Educational Psychology, 87, 406-423.

Williams, F. E. (1972). Identifying and measuring creative potential. New Jersey: Educational Technology Publications.

Wu, J. H., Wang, S. C., \& Tsai, H. H. (2010). Falling in love with online games: The uses and gratifications perspective. Computers in Human Behavior, 26(6), 1862-1871.

Xiao, L., \& Martin, J. (2012, February). Supporting parent-young child activities with interactive 
Australasian Journal of Educational Technology, 2014, 30(6).

tabletops: A conceptual analysis. Paper presented at the ACM 2012 Conference on Computer Supported Cooperative Work Companion, Seattle, Washington, USA.

Corresponding author: Cheng-Sian Chang, chengsian1117@gmail.com

Australasian Journal of Educational Technology (c) 2014.

Please cite as: Hsiao, H-S., Chang, C-S., Lin, C-Y., Chang, C-C., \& Chen, J-C. (2014). The influence of collaborative learning games within different devices on student's learning performance and behaviours. Australasian Journal of Educational Technology, 30(6), 652-669. 